ARTICLE

https://doi.org/10.1057/s41599-019-0262-5

\title{
Girls' perceptions of boys with violent attitudes and behaviours, and of sexual attraction
}

\author{
Lidia Puigvert ${ }^{1}$, Loraine Gelsthorpe ${ }^{2}$, Marta Soler-Gallart ${ }^{1} \&$ Ramon Flecha $^{1}$
}

\begin{abstract}
Violence against women is a reality that is still present in Europe and a serious public health threat worldwide. Fortunately, investment is being made to raise awarness at the national and EU levels and among diverse publics. However, more research is needed in order to better explain its underlying factors, and thus identify effective actions that could contribute to preventing young girls and women from becoming victims. Drawing on a theoretical approach to the preventive socialization of gender violence, in this study we report data from the quasi-experimental research project 'Free Teen Desire' (Marie SklodowskaCurie Grant, 2015-2016, No 659299). Through a survey conducted on 100 female adolescents (aged 13-16) in different European secondary schools (in England, Spain, Cyprus and Finland), we analysed their pattern of attraction for both 'hooking up' and stable relationships towards boys with either violent attitudes and behaviour or boys with non-violent behaviour, what would be linked to gender violence victimization at a later stage in their lives. Our findings suggest that in the different European secondary schools studied, a similar pattern of attraction is recognized by female participants: although non-violent boys are highly preferred to those with a violent profile, we observed that boys with violent attitudes and behaviours are mostly preferred for hooking up, and boys with non-violent traits are mostly preferred for stable relationships. In addition to the novelty of providing quantitative data on these links (non-violent/stable relationships; violent/hook-ups) in the case of adolescents, the findings regarding the pattern of attraction towards boys with violent traits for sporadic relationships are in line with previous extensive qualitative research. This body of research marks the existence of a coercive dominant discourse that associates attraction with violence and influences the socialization processes of many girls during their sexual-affective relationships' awakening, which has been shown to constitute a risk factor for gender violence victimization.
\end{abstract}

\footnotetext{
${ }^{1}$ Department of Sociology, University of Barcelona, Barcelona, Spain. ${ }^{2}$ Institute of Criminology, University of Cambridge, Cambridgeshire, Cambridge, UK. Correspondence and requests for materials should be addressed to L.P. (email: lidia.puigvert@ub.edu)
} 


\section{Introduction}

n 2013, the World Health Organization, the London School of Hygiene and Tropical Medicine and the South African Medical Research Council published a report on 'Global and regional estimates of violence against women: prevalence and health effects of intimate partner violence and non-partner sexual violence'. The report constituted the first global systematic review and synthesis of scientific data on two forms of violence against women: violence by an intimate partner (intimate partner violence) and sexual violence by someone other than a partner. It reveals that $35 \%$ of women worldwide have experienced either physical and/or intimate partner violence or sexual violence by a non-partner at some point in their lives; almost a third of all women who have been in a relationship have experienced physical and/or sexual violence committed by their intimate partner. Beyond this, at the global level, $38 \%$ of all murders of women are committed by intimate partners, and women who have suffered physical or sexual abuse by their partners suffer from serious health problems at a later stage (WHO, 2014).

Although resources have been invested in programmes and campaigns by European institutions, and legislation has been passed in the EU in order to pressure member states to act upon the issue of gender violence, figures reveal that there has been little change in practice. In this regard, in 2014, the European Union Agency for Fundamental Rights (FRA) published a report called the 'Violence against women: an EU-wide survey' (FRA, 2014). This report gathered data from the 28 European member states on experiences of physical, sexual and psychological violence, including intimate partner violence (domestic violence) and sexual harassment. The FRA declared that violence and abuse are affecting the lives of European women but that this situation is being systematically under-reported to the authorities. Data collected in the survey indicates that an estimated 13 million women in the EU had experienced physical violence in the course of 12 months before the survey interviews, and an estimated 3.7 million women in the EU had experienced sexual violence in the course of 12 months before the survey interview. Regarding minors, FRA figures revealed that one in three girls and young women had experienced physical and/or sexual violence by the age of 15 years old and that out of all women who had a (current or previous) partner, $22 \%$ had experienced physical and/or sexual violence committed by a partner since the age of 15 . Regarding non-partner violence, one in five women had experienced physical violence committed by someone other than their partner since the age of 15 .

As observed, violence against women is a reality that is still present in Europe and a serious public health threat worldwide, which fortunately is being addressed more and more with the aim of tackling its multiple manifestations, from the domestic sphere to the trafficking of human beings, considering its gendered dimension (Limoncelli, 2017). However, more research is needed in order to inform two central socio-legal debates related to the prevention and tackling of gender violence: on the one hand, how to unveil effective actions that prevent girls and young women from falling in the coercive dominant discourse that fosters attraction towards violence (Puigvert, 2014; Racionero-Plaza et al., 2018), and on the other hand, to contribute to sensitizing the penal systems in the EU to gender differences (Burman and Gelsthorpe, 2017; Gelsthorpe, 2017) while providing insights on how to advance legislation of consent and, specifically, on the affirmative 'yes' (Vidu and Tomás-Martínez, 2019). In this sense, an in-depth analysis of this complex problem should help us to better recognize which of the risk factors already identified in the literature are the ones which are more prominent in perpetuating the cycle of the violent victimization of youth.
A coercive dominant discourse: attraction to violence. Research on risk factors related to gender violence conducted from a preventive socialization approach has identified that there is a coercive dominant discourse in which people with violent attitudes and behaviours are socially portrayed as attractive and exciting. On the other hand, people and relationships with nonviolent attitudes and behaviours are portrayed as less exciting (Gómez, 2015; Soler-Gallart, 2017). Accordingly, due to imbalanced power relationships between men and women, this coercive dominant discourse (e.g., through TV, teen magazines, social networks, popular media, among other things) influences many girls' and women's socialization into linking attractiveness to people with violent attitudes and behaviours.

Different qualitative investigations have analysed the impact of this coercive dominant discourse. In this regard, research on the 'Impact of communicative acts and new masculinities' (SolerGallart, 2008-2011) conducted with adolescents showed how some communicative acts (those acts that include not only speech acts but also other types of communication) reinforced hegemonic masculinities, which are the ones linked to dominant and violent attitudes and behaviours. However, other communicative acts, based on dialogic interactions, contribute to better recognizing new masculinities, which are represented by boys who reject violence while maintaining desirability. Oliver (2010-2012) directed a research project in order to deepen our understanding of what has been defined by Flecha and Puigvert as the 'mirage of upward mobility', the mistaken perception of some girls and young women who believe that having a sexual-affective relationship with boys/men who respond to the hegemonic model of masculinity (Connell, 2012) will lead to an increase in their status and attractiveness. Nonetheless, research has revealed that in these cases, instead of increasing the girls' or young women's status or attractiveness, it decreases those qualities (Tellado et al., 2014). In turn, girls who fall for the mirage of upward mobility more easily identify when other girls go through this mirage than when it affects themselves (Puigvert, 2015-2016).

The Free_Teens_Desire project (2015-2016), in which the present study is framed, also investigated to what extent dialogue situations based on a 'language of desire' instead of on a 'language of ethics' can question adolescent girls' desires that link attractiveness to violent behaviours, gathering for the first time quantitative data on this link (Puigvert, 2015-2016). The language of ethics is often used to educate children in a nonsexist way, in both home and school contexts (Rios-González et al., 2018). Parents and teachers thus talk about what 'is good' or what 'should be done', using cognitive schemata to assess sexualaffective lives that are grounded in ethics. In the case that is under examination here, the employment of a 'language of ethics' when talking about men with violent behaviour and attitudes would imply that adults are saying something such as 'that boy is not convenient for you', 'he is a bad boy' or 'he has inappropriate behaviour'. Dialogues using the language of ethics are sometimes seen by adolescents as boring, unattractive or 'moralistic'. In contrast, a 'language of desire' predominates among adolescents' dialogues; this language is also used by media, in social networks and in those contexts which adolescents consider attractive. The language of desire is not exerted within the realm of ethics, but within the realm of aesthetics, taking into account adolescents' desires and likes; as a result, this triggers emotions and actions. The disassociation between both types of languages and the 'language of desire' missing from many gender violence campaigns prevents them from being effective. In not using the language which adolescents and the media tend to use, the campaigns do not challenge the dominant model of socialization 
and the association between violence and attraction that this imposes (Flecha and Puigvert, 2010).

Building upon the findings of research studies on the preventive socialization approach, three different masculinity models have been recognized and accordingly theorized (Flecha et al., 2013). These are considered as ideal types in a Weberian way, identified in order for us to be able to develop social theory. First, the Dominant Traditional Masculinities (DTM) is the model represented by those men who embrace the values of the patriarchal society and consider themselves to be the ones who 'know about sex', and they are sometimes linked with violent attitudes. Second, the Oppressed Traditional Masculinities (OTM), the model which, drawing from a perspective merely limited to the language of ethics, is represented by those men who hold egalitarian values but are considered 'not sexy'. In this second model, the capacity to increase attraction and be desired has not yet been transformed, so they are not an alternative to gender violence, as they do not challenge the values embodied by the DTM. Radically opposed to OTM and DTM are the New Alternative Masculinities, a model situated within the realm of language of desire, represented by men who oppose violent attitudes and behaviours while also being considered sexy.

When is the risk taken? Hook-ups vs. stable relationships with men with violent attitudes and behaviours. Research in the field of psychology has also studied how, under certain conditions, aggressive men and those men considered more masculine are preferred to other men. Giebel and colleagues (2013) conducted a study in which they analysed whether appetitive aggression in men serves as an additional signal for a favoured partner choice. The authors defined appetitive aggression as 'the intrinsic motivation to act violently even when not being threatened' (p. 248). Testing participating women's responses in relation to different descriptions regarding a soldier's experience after returning from war, they observed that the preference for the 'warrior' was higher for women in their fertile window of the menstrual cycle and for short-term relationships. Accordingly, their findings reveal that women preferred a soldier higher in appetitive aggression as a short-term mate but not as a partner in a long-term relationship.

In another research study, Giebel et al. (2015) investigated personality traits and to what extent these traits predict the desire to choose a dominant partner. The authors observed that those individuals who declared wanting to avoid boredom and looked for exciting social activities have a stronger desire for a dominant partner. According to this study, those perceived as dominant are considered more interesting, attractive and appealing for people with higher boredom susceptibility. Additionally, people who like new and exciting social activities such as parties, social drinking and casual sex also prefer a dominant partner. In a similar vein to this investigation, Houser et al. (2015) observed that dating preferences were positively correlated with popularity, social preference and overt and relational aggression. Popular and overtly aggressive girls were seen as desirable dating partners by their male peers, and relational aggression was linked with dating popularity for both boys and girls.

On dating violence in adolescence and young adulthood. Participants in current debates on increasing rates of violence among young people agree that some specific types of experience, such as adolescents' experience of violence during intimate partner relationships, including former or present long-term partners and dating violence (violence occurred in sporadic relationships or hook-ups), are a growing problem and an increasing concern (Erickson et al., 2010; Bramsen et al., 2012; Leen et al., 2013). Dating violence perpetration and victimization is of major relevance, especially considering the influence that it may have on future intimate partner violence and, as highlighted by Theobald and colleagues (2016), the burden of coping with violence from one generation to the next (p. 225).

Within the field of criminology, many researchers are advancing knowledge about the risk factors that may lead to dating violence. In this regard, Rebellon and Manasse (2004) investigated the association between delinquency and other risktaking behaviours with dating behaviour among adolescents, showing that delinquency serves to increase romantic involvement. According to their results, risk-taking adolescents attract the romantic interest of others, and such attention may provide indirect reinforcement for delinquency among both male and female adolescents. In a different study about risk factors for first time sexual assault, Bramsen et al. revealed that the 6-month period following the 15th birthday is characterized by a high risk for initial sexual victimization by peers (Bramsen et al., 2012, p. 524). Authors identified two elements that predicted initial adolescent peer-on-peer sexual victimization (APSV): first, the number of sexual partners, and second, sexual risk behaviours that place girls in close association or proximity to potential offenders.

At the core of identifying these violent situations lies the idea suggested by some authors, that victimization and revictimization are either caused by an impaired ability to recognize potentially threatening situations (Bramsen et al., 2011; Messman-Moore and Brown, 2006) or are a function of how youths perceive common dating risk situations that may place them at risk not only of suffering dating violence but also a variety of other problematic behaviours (Helm et al., 2015). In this line, it has also been suggested that among those adolescents with high acceptance of dating aggression, peer aggression and delinquency significantly predicted recurrent aggression in a new relationship (Williams et al., 2008).

Research has also found that some adolescents tend to maintain violent dating relationships that become chronic, and some teens engage in multiple violent relationships in which the severity of violence increases from the first to subsequent relationships (Burke Draucker et al., 2012). There is evidence that intimate partner violence and violence in hook-ups is widespread among adolescents and young adults and leads to a life trajectory that includes violence, either as victims or perpetrators (Bramsen et al., 2011; Burke Draucker et al., 2012; Exner-Cortens et al. 2013; Lundgren and Amin, 2015). As mentioned above, peer influences and attitudes towards violence (e.g., acceptance of rape myths, tolerance of violence, and justification of using violence) appear to be the most extensively evidenced risk factors for dating violence perpetration (Bramsen et al., 2011; Tapp and Moore, 2016).

All in all, the present article draws, on the one hand, on classic works of feminist authors such as Mary Wollstonecraft (1972) who in the 18th century, advocated for the rights of women to receive the education needed to realize their full faculties and rights on equal footing with men. On the other hand, it draws on the large amount of current literature on associated risk factors for violence perpetration and victimization. This work adds to these bodies of literature by introducing quantitative data on the female adolescents' pattern of attraction towards either boys with violent attitudes and behaviours or boys with non-violent traits, looking at the differences in such attraction patterns when the young women consider either hook-ups or stable relationships. Despite reporting data on both violent and non-violent boys, the analysis is mostly focused on the scenarios involving boys with violent behaviours, as these are the ones at the very centre of the coercive socialization that leads to the link between attraction and violence. Unveiling the mechanisms behind this coercive 
discourse and how it operates in a different way in hook-ups and in stable relationships will help to contribute to prevention strategies of gender violence as well as to untangle how violence acts as an underlying force within the current patriarchal system, perpetuating the coercive model of socialization.

\section{Methods}

Findings reported in this article are the result of a quasiexperimental exploratory case study, framed within the Free_Teen_Desire project (2015-2016) funded by the Marie Sklodowska-Curie Actions. This project was designed in order to collect a first-time set of quantitative data that would back previous qualitative research on gender violence victimization that links attraction with violence among young people, and more generally, it aimed at measuring female teenagers' desire to either have a hook-up or establish a stable relationship with boys who are described as having violent attitudes and behaviours.

This quasi-experimental exploratory case study was conducted in four secondary schools located in four European countries: Cyprus, Spain, Finland and the UK. Schools where the study was carried out were selected according to an intentional sample, following two criteria: a) partnership schools, namely: in each of the countries, schools with which the research team have established collaboration in previous research investigations about the research line on preventive socialization of gender violence; b) diversity in relation to geographical location, urban vs rural condition, socioeconomic status, culture, ethnicity and religion.

Regarding case study participants, the research team agreed with the head teacher of each school on the possibility for all girls from 13 to 16 years old to be part of the study. The school centre assessed and decided whether it would be better for any one student to not be included as a participant and provided the necessary information to justify the decision. Thus, the final female student participants in each case study were those who, after hearing an in-depth explanation of the investigation and its objectives and following strict ethical procedures due to the sensitiveness of the topic, decided to take part in it. Eventually, a total of 100 female teenagers participated in the study, ranging from 13 to 16 years old. Participants' distribution was as follows: Cyprus $=15$; Spain $=36$; Finland $=34$, and UK $=15$. From the UK sample of students, 8 out of the 15 participants were reached not through a secondary school (although they were secondary school students) but through an NGO working with ethnic minorities groups which collaborated with the research coordinating team. The same procedure for female participants selections was followed.

Regarding the participants' ethnic diversity, except for the case of the UK where there was a high rate of diversity $(46.7 \%$ of student participants were white, and the rest from other cultural minorities, including Roma and Muslim), in the secondary schools of the other three countries, more than the $80 \%$ of female participants were white.

The quasi-experimental and exploratory nature of the case study explains that results presented in this specific research are not generalizable to different realities than the included ones. Although caution should be paid with respect to the cases of the UK and Cyprus, given their small number of respondents, a key methodological interest of this study lies in its replicability in diverse countries. Future similar research can replicate the quasiexperiment with larger samples, testing the replicability of patterns identified while unveiling newer trends.

Instrument. We used an experimental vignette-based methodology (EVM) to examine girls' responses to different situations in which a boy and his profile are presented to the audience
(Aguinis and Bradley, 2014). This type of approach has been largely used in gender studies (Sleed et al., 2002; Crawford and Popp, 2003). Previous investigations suggest that EVM has high levels of confidence regarding internal validity and that they allow study participants to explore their experiences regarding sensitive matters on their own terms from a safer and less threatening perspective. Hence, EVM is a methodological strategy that allows participants to reach greater levels of honesty and reduce the risk of social desirability (Barter and Renold, 1999). For instance, asking the subjects to share stories and memories about their friends rather than about themselves or doing both.

The Vignette-Test designed for the Free_Teen_Desire project consisted of a set of three types of vignettes (A-B-C) distributed among the different students' groups/countries. For the study we are reporting here, we worked with the vignettes set $C$. Each set of Vignette-Test consisted of four different vignettes. Each one portrayed a boy with a brief description, mainly in terms of his attractiveness and his behaviour and attitudes regarding women. Two of the vignettes (boy 1 and boy 3 ) each portrayed a picture of a boy accompanied by a brief narrative which included some sentences on behaviours and attitudes considered to be violence against women by international scientific literature (Banyard et al., 2005; Fisher et al., 1999; Kalof et al., 2001; Gross et al., 2006). The other two vignettes also portrayed two different pictures accompanied with a description that included non-sexist behaviours (boy 2 and boy 4 ).

The two boys' profiles classified as the ones with violent attitudes and behaviours in the Vignettes set $\mathrm{C}$ were described as follows:

Boy 1. He is a funny bastard. He seems disinterested in girls and can't even remember their names after hooking up with them... In fact, he laughs at his friends who act like that... by that point some girls want to be with him again, and he disdains them persistently. He is not as sensible and good as his friends are, but his strong temper makes him somebody interesting to be discovered. Lots have tried to. $\mathrm{He}$ is someone to be rescued. He has a difficult personality.

Boy 3. You want not to like him but his hypnotic eyes will hook you. You will probably be just another girl he's been with but most are not ashamed to admit they dream to be the one to save him. Despite the fact that he has touched them without consent, they believe they can change him. He's totally the hottest boy. His personality is scary, but it will make you drool.

On the other hand, the two boys' profiles described as nonviolent in the Vignettes set $\mathrm{C}$ were presented in the following way:

Boy 2. He is the boy every girl dreams to be with for the rest of her life; well-mannered, courteous, respectful of everyone. He knows how to treat girls as queens. He cares and is attentive. My friends say it's a pity he is not manlier.

Boy 4. Open and friendly, he makes girls feel comfortable. He's nice, funny, dedicated and makes interesting conversations. He is the good-hearted guy that mothers love.

Participants had to respond to six different questions related to their own interest, the interest of their friends and the interest of 'other girls they know' in either hooking up or establishing a relationship with the boys portrayed in the vignettes:

(1) Would you like to hook up with him at a party?

(2) Would you like to have a relationship with him?

(3) Would your friends like to hook up with him at a party?

(4) Would your friends like to have a relationship with him? 
(5) Would other girls you know like to hook up with him at a party?

(6) Would other girls you know like to have a relationship with him?

Thus, drawing on the data collected, we wanted to examine the different female adolescents' preferences between two opposed boys' profiles described in the vignettes, those males with violent attitudes and behaviours and those males who were non-violent, for two different types of relationships: hooking up or a stable relationship. In addition, differences when answering considering their own preferences, the preferences that the female adolescents thought that their friends would have, and the ones that 'other girls they know' would have were tested in searching for any relevant contrast. To collect the answers, we used a Likert scale with 6-positions (from 1 meaning "totally not", to 6 meaning "totally yes."). It took approximately 10 to $15 \mathrm{~min}$ to respond to all the questions included in the survey.

Female students who participated in the study passed through the international ethical standard process in research that ensured that their anonymity will be maintained throughout all of the investigation process and afterward. Particularly, this investigation met the ethical review process of Marie Skłodowska-Curie Actions under the Horizon 2020 programme. Each participant was provided with a Consent Form and Information Sheet elaborated with language adapted to this particular age range. They had the necessary time to read it carefully, and when they agreed, they were asked to sign it. Furthermore, Consent forms for the parents or tutors were distributed together with specific information sheets. Beyond the distribution of the Consent forms for parents, the research team offered the possibility of carrying out an information meeting in the school for the parents of the study participants.

Data analysis. The analysis was conducted considering the secondary schools in each country. For the case of the UK and in order to simplify the analysis, the two high schools were grouped into one (cases were added). The $n$ (female participants) per case, as mentioned above were: Cyprus $=15$; $\mathrm{UK}=15$; Spain $=36$; Finland $=34$.

A descriptive analysis was done based on the six questions approached in the aforementioned tests. We used SPSS (version 24) for statistical analysis purposes, and we grouped the 1 to 6 positions of the Likert scale in two dichotomy variables: positions 1 to 3 signified 'No' (respondents who would not like to hook up or establish a relationship with (a) a boy described with violent traits, (b) a boy described as kind and with non-violent traits), positions 4 to 6 signified 'Yes' (respondents who would like to hook up or establish a relationship with (a) a boy described with violent traits, (b) a boy described as kind and with non-violent traits. We used a T-test (paired sample) with the aggregated data in order to analyse if there was any significant difference between boy 1, boy 2 , boy 3 and boy 4 when the participants answered that either their friends or other girls they know would like to hook up or establish a relationship with one of them.
After conducting the survey, we used a Cronbach test to check the reliability of the data collected. The result indicates an acceptable internal consistency (Cronbach's alpha $=0.703$ ).

\section{Results}

In what follows, we present the results according to the secondary schools of each country and the two possible types of relationships (hook-up and stable relationship) disaggregated by subjects asked: themselves, their friends, and other girls. Answers are also distributed among the four boys' profiles, 'boy 1' [Violent 1] and 'boy 3' [Violent 3]; 'boy 2' [Non-violent] and 'boy 4' [Nonviolent].

It is notable in this first scenario that, in many cases, there are up to 20 points of difference between the hook-up (more preferred), and the situation of a stable relationship (less preferred) for the same boy for (See Table 1).

Unfolding the implications of the coercive dominant discourse: boys described with violent traits mostly preferred for hooking up. An initial observation for the three situations presented in the vignette survey is that non-violent boys are preferred, in general terms, to a higher extent than those with violent traits. This is very positive as a general overview. However, in order to better understand potential situations of gender violence victimization, other trends which emerged in the results need to be carefully looked into and interpreted.

First, female participants respond that the two boys described with violent behaviours and attitudes are chosen to a higher extent for hook-ups rather than for establishing stable relationships. This trend is clearly observed for the case of the secondary school from Finland and Spain for both boys described with violent traits (boy 1 and boy 3). In the case of UK and Cypriot schools, the results observed are slightly different as an even pattern is not appreciated. In the UK, boy 1 is mostly preferred for hook-ups, and boy 3 is equally preferred for hook-ups and stable relationships. In the case of Cyprus, boy 1 and boy 3 are still much preferred for hooking up but not in all situations.

To better clarify this trend, Table 2 summarizes the participants' preference in terms of type of relationship (hooking up or stable relationship). In this table, for every violent boy, we count the number of participants who declare they prefer that boy for a hooking up rather than for a stable relationship. "Yes" means that participants in the survey prefer that boy for hooking up rather than a stable relationship. In turn, for every non-violent boy, we also count the number of participants that prefer them but for a stable relationship. Hence, in those cases, 'Yes' means that participants prefer the non-violent boy for a stable relationship, rather than for hooking up with him. In the table, we also show the cases in which these trends do not happen; in those cases, a 'No' label is added in the table (in the corresponding cell). Whenever there is no possible way to establish a preference for either the violent or the non-violent boy, then an equal sign $(=)$ is used in the table.

Table 1 Secondary schools by types of relationships and subject asked (\%)

\begin{tabular}{|c|c|c|c|c|c|c|c|}
\hline \multicolumn{4}{|c|}{ Secondary School Finland } & \multicolumn{4}{|c|}{ Secondary School Spain } \\
\hline \multicolumn{2}{|c|}{ Violent } & \multicolumn{2}{|c|}{ Non-violent } & \multicolumn{2}{|c|}{ Violent } & \multicolumn{2}{|c|}{ Non-violen } \\
\hline B1 & B3 & B2 & B4 & B1 & B3 & B2 & B4 \\
\hline 15 & 35 & 53 & 47 & 33 & 36 & 50 & 61 \\
\hline 0 & 24 & 82 & 71 & 11 & 14 & 69 & 61 \\
\hline 26 & 50 & 71 & 50 & 47 & 47 & 56 & 53 \\
\hline 9 & 36 & 88 & 71 & 28 & 25 & 78 & 58 \\
\hline 53 & 79 & 68 & 50 & 92 & 83 & 53 & 58 \\
\hline 27 & 76 & 79 & 68 & 64 & 58 & 69 & 64 \\
\hline
\end{tabular}

\begin{tabular}{|c|c|c|c|}
\hline \multicolumn{2}{|c|}{ Violent } & \multicolumn{2}{|c|}{ Non-violen } \\
\hline B1 & B3 & B2 & B4 \\
\hline 7 & 20 & 47 & 53 \\
\hline 0 & 20 & 60 & 53 \\
\hline 33 & 53 & 67 & 67 \\
\hline 13 & 53 & 80 & 67 \\
\hline 60 & 67 & 67 & 67 \\
\hline 40 & 53 & 73 & 60 \\
\hline
\end{tabular}

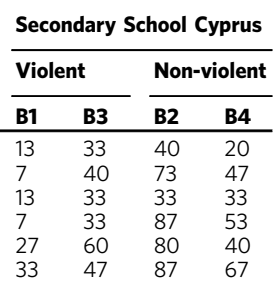


Table 2 Violent profiles mostly preferred for hooking up? Non-violent profiles mostly preferred for stable relationships?

\begin{tabular}{|c|c|c|c|c|c|c|c|c|c|c|c|c|c|c|c|c|}
\hline & \multicolumn{4}{|c|}{ Secondary School Finland } & \multicolumn{4}{|c|}{ Secondary School Spain } & \multicolumn{4}{|c|}{ Secondary School UK } & \multicolumn{4}{|c|}{ Secondary School Cyprus } \\
\hline & \multicolumn{2}{|c|}{ Violent } & \multicolumn{2}{|c|}{ Non-violent } & \multicolumn{2}{|c|}{ Violent } & \multicolumn{2}{|c|}{ Non-violent } & \multicolumn{2}{|c|}{ Violent } & \multicolumn{2}{|c|}{ Non-violent } & \multicolumn{2}{|c|}{ Violent } & \multicolumn{2}{|c|}{ Non-violent } \\
\hline & B1 & B3 & B2 & B4 & B1 & B3 & B2 & B4 & B1 & B3 & B2 & B4 & B1 & B3 & B2 & B4 \\
\hline Themselves & Yes & Yes & Yes & Yes & Yes & Yes & Yes & $=$ & Yes & $=$ & Yes & $=$ & Yes & Yes & Yes & Yes \\
\hline Their friends & Yes & Yes & Yes & Yes & Yes & Yes & Yes & Yes & Yes & $=$ & Yes & $=$ & Yes & $=$ & Yes & Yes \\
\hline Other girls & Yes & Yes & Yes & Yes & Yes & Yes & Yes & Yes & Yes & Yes & Yes & No! & No! & Yes & Yes & Yes \\
\hline
\end{tabular}

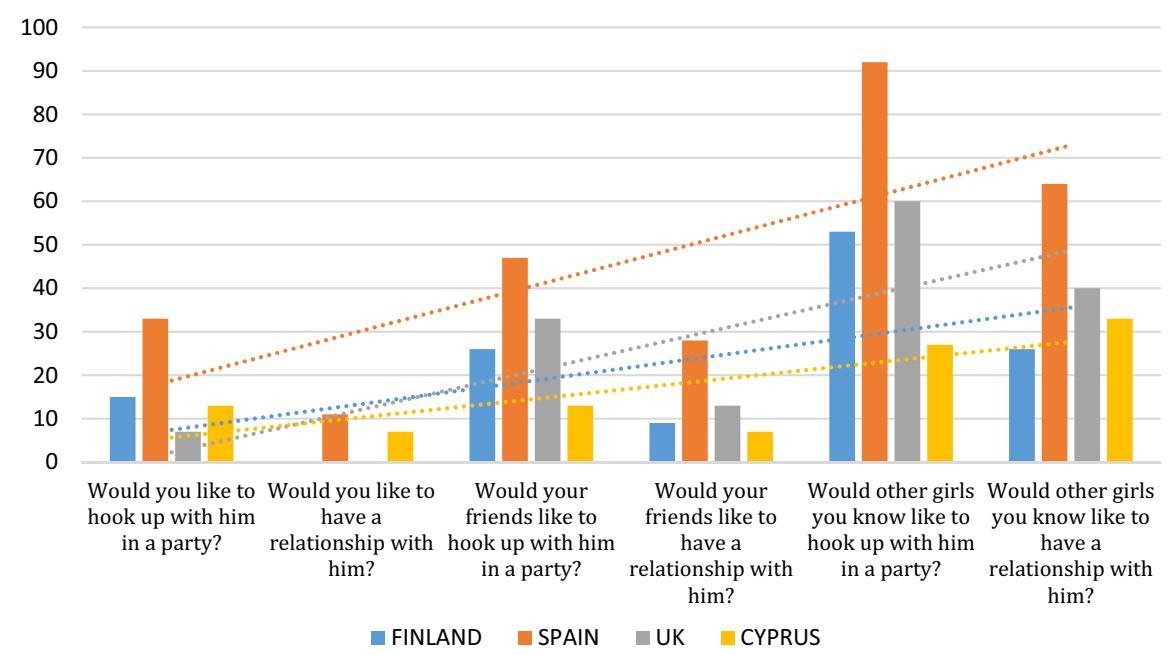

Fig. 1 Hook up/Stable relationship with a boy with violent behaviour [Boy 1]. Trends observed in the female participants' answers for Boy 1 [Violent profile] disaggregated according to a subjects asked about (themselves, their friends, and other girls) and $\mathbf{b}$ type of relationships (hook-up and stable relationship)

When looking at the data and paying attention to the answers about the preferences for boys with non-violent attitudes and behaviours (boy 2 and boy 4), it is clear they are, in most situations, largely preferred for stable relationships rather than for hook-ups. Again, this is clearly observed in the cases of Finland, Spain, and Cyprus, and of uneven frequency in the case of the UK when looking at boy 4 .

Boys with violent attitudes and behaviours chosen to a higher extent when answering thinking about preferences of 'their friends' and 'other girls'. When solely focused on the cases of boys described as having violent attitudes and behaviours, as observed in Figs 1 and 2, it is clear there are sharp differences among the answers for the categories of 'themselves', 'friends' and 'other girls'. Percentages of positive answers related to the preferences to either hook up or have a relationship with either boy 1 or boy 3 , according to female respondents, are the highest when they answer thinking about 'other girls they know'. When participants answer thinking about the preferences of 'their friends', the percentages decreased in comparison with the ones of the 'other girls'. In addition, finally, when they answer thinking about their own preferences, the percentages are the lowest. The observed trend is that the more distance there is among female participants themselves and the subjects for whom they are answering (their friends or other girls), the higher the percentage of positive answers for either hooking up or having a relationship with the boys with violent behaviours.

Taking the case of the Finnish secondary school as an illustrative situation, if we analyse the answers regarding boy 1 , it can be observed that $15 \%$ of the female teenagers who answered that question would like to hook up with a boy with violent behaviours. However, when they are asked about the same boy when thinking about a friend, the answer rises to $26 \%$. This increase is even more accentuated when participants are asked, in the same situation, about other girls: the percentage goes up to $53 \%$. The same occurs for this same case (Finland) for boy 3 and the category of 'hook up'. This same trend is observed for the Spanish and Cypriot secondary schools.

Cross-tabulation analyses were carried out in order to confirm the relation observed in the frequency table (Table 1) about preferences for boys with violent traits between the type of relationship explored (hooking up and stable relation) and the person with whom they would like to have the relationship (themselves/friends/other girls). The reduced number of cases for each secondary school case study hampered the cross-tabulation analysis, also taking into account the different context. For this reason, different cases were grouped together for the analysis. However, this did not impede the observation of significant correlations. Cross-tabulation results for Boy 1 and Boy 3 (violent profiles) are presented in Tables 3 and 4 .

Results from Table 3 indicates that, for instance, for boy 1, among those girls who answer that they themselves would like to hook up with a boy with violent attitudes and behaviours ( $n$ $20=100 \%$ ), only $20 \%$ of them would also have a stable relationship with them (See crosstab 3.1). When answering thinking about their friends, the results increase: according to respondents, of those who would like to hook up with a boy with violent attitudes and behaviours (n $33=100 \%$ ), $45.5 \%$ of them would also like to have a stable relationship with him (See crosstab 3.2). Finally, when thinking about "other girls they know", among the total of those who would like to hook up with a boy with violent behaviours $(n 63=100 \%)$, more than half of them would also like to establish a stable relationship, $66.7 \%$ (See crosstab 3.3).

This same trend is observed in Table 4, regarding the case of boy 3 and is in some categories even more accentuated. Of those 


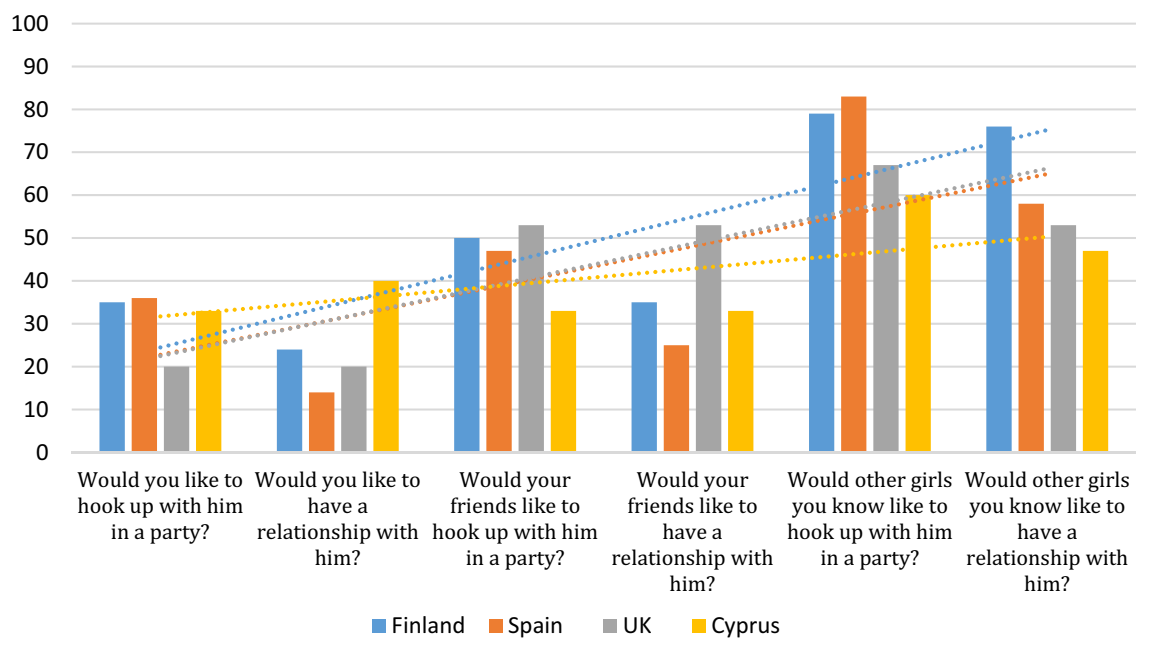

Fig. 2 Hook up/Stable relationship with a boy with violent behaviour [Boy 3]. Trends observed in the female participants' answers for Boy 3 [Violent profile] disaggregated according to a subjects asked about (themselves, their friends, and other girls) and $\mathbf{b}$ type of relationships (hook-up and stable relationship)

\section{Table 3 Cross tables hooking up/stable relationship, Boy 1 [violent]}

\section{Crosstab 3.1: yourself}

Would you like to hook up with him at a party?

Would you like to have a relationship with him?

No Yes $\quad$ Total

$\begin{array}{lll}16 & 4 & 20\end{array}$

Pearsons chi-square analyses of cross tab 3.1

$80 \%$

$20 \%$

$100 \%$

Pearsons chi-square

Continuity correction ${ }^{b}$

Value

$11.842^{\mathrm{a}}$

8.224 df

$1 \quad 0.003$

\section{Crosstab 3.2: your friends}

Would your friends like to hook up with him at a party?

Would your friends like to have a relationship with him?
$\begin{array}{lll}\text { No } & \text { Yes } & \text { Total } \\ 18 & 15 & 33 \\ 54.5 \% & 45.5 \% & 100 \%\end{array}$

Pearsons chi-square analyses of crosstab 3.2

Pearsons chi-square

Value $\quad \mathrm{df}$

Continuity correction

31.794

28.607

df

1
Asymp. Sig. (2-sided)

0.000

0.000

\section{Crosstab 3.3: other girls you know}

Would other girls you know like to hook up with him at a party?

Pearsons chi-square analyses of crosstab 3.3

Pearsons chi-square

Continuity correction ${ }^{f}$

$\begin{array}{lll}\text { Would other girls you know like to have a relationship with him? } \\ \text { No } & \text { Yes } & \text { Total } \\ 21 & 42 & 63 \\ 33.3 \% & 66.7 \% & 100 \% \\ & & \\ \text { Value } & \text { df } & \text { Asymp. Sig. (2-sided) } \\ 38.060^{e} & 1 & 0.000 \\ 35.504 & 1 & 0.000\end{array}$

a 2 cells $(50 \%$ have expected count less 5 . The minimum expected count is 1.00

bComputed only for $2 \times 2$ table

${ }^{\mathrm{C}} \mathrm{O}$ cells $(0.0 \%)$ have expected count less than 5 . The minimum expected count is 5.28

dComputed only for a $2 \times 2$ table

a Computed only for a $2 \times 2$ table
e cells $(0.0 \%)$ have expected count less than 5 . The minimum expected count is 15.64

${ }^{e} 0$ cells $(0.0 \%)$ have expected coun
fComputed only for a $2 \times 2$ table

girls who would like to hook up with a boy with violent attitudes and behaviours, $13.6 \%$ of them would also like to have a stable relationship with him (See crosstab 4.1.). When asked about their friends, of those who would like to hook up with boy 3, 58.7\% would also establish a stable relationship with him (See crosstab 4.2). In addition, when asked about "other girls they know", among those who answer positively about wanting to hook up with a boy with violent attitudes and behaviours, $77.6 \%$ would also like to have a stable relationship with him (See crosstab 4.3).

The two patterns revealed by frequency analysis are therefore reaffirmed by cross-tabulation analysis. First, boys with violent behaviours and attitudes are chosen to a lesser extent than the ones with whom girls want to establish a stable relationship rather than just hook up. Second, the more distance between the 


\section{Table 4 Cross tables hooking up/stable relationship, Boy 3 [violent profile]}

\section{Crosstab 4.1: yourself}

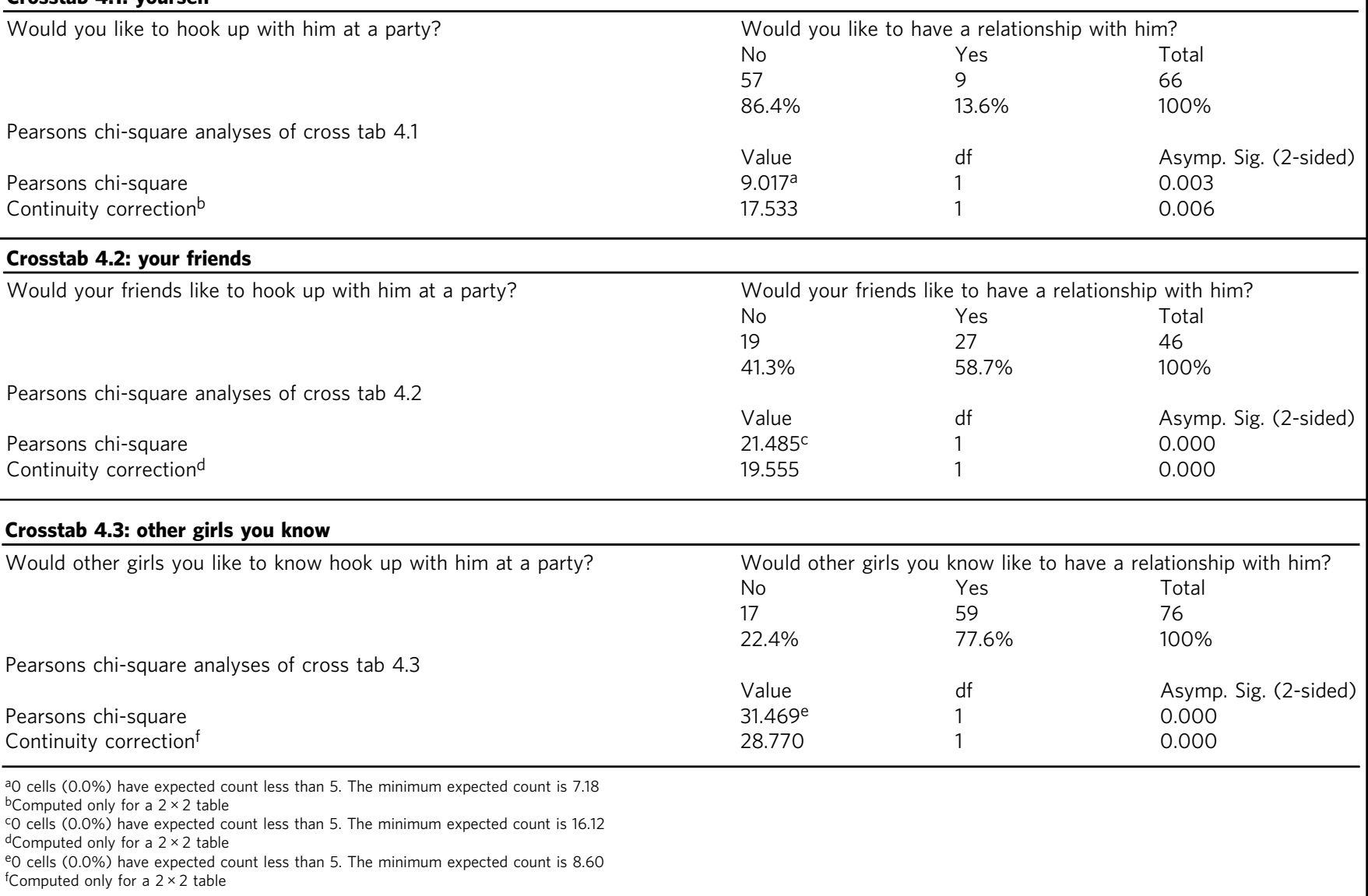

respondent and the subject about whom is asked (friends, other girls), the higher the positive rate of answer about the wish to both hook up and establish a stable relationship. According to the Chi-Square test, the relationship between the variables included in the cross-tabulations analyses seems not to be based on random relationships but on real ones (See the Pearson ChiSquare tables included above, for each crosstab analyses).

Although the general interest of this research relies on analysing the pattern of preferences for the violent profiles (boy 1 and boy 3), in order to be consistent, crosstabulation analyses were also conducted for the non-violent profiles of boy 2 and boy 4. Results are showcased in Table 5, for non-violent boy 2 , and in Table 6, for non-violent boy 4 . Trends observed in both tables are of a similar type: for boy 2 and boy 4 , and for all situations asked about (themselves, their friends, and other girls), percentages of affirmative answers are over $85 \%$, and according to a Chi-Square test, of significance. This means that among all those who would choose a non-violent boy for a hook-up, most of them would also choose him for a stable relationship.

No relevant differences among the secondary schools: challenging the contexts. The third pattern that can be observed in the data is that if we look at it according to the four schools where the study was carried out, no major differences between them emerge. What this suggests is that for the cases studied, there is no influence of what might be termed 'the cultural context of the country' on the preferences of the female adolescents participating in the study. This is of relevance as it challenges some vivid cultural stereotypes and prejudices that relate the existence of gender violence to specific contexts (more deprived) or to cultural and ethnic backgrounds.

Results presented in this investigation are limited to a small sampling. However, more research is currently being conducted in the framework of the Free_Teens_Desire project in order to contest, for instance, the idea that gender violence victimization is more present among cultural minorities. Thus, research in the field of gender violence needs to show the interaction between gender and racial discrimination and stigmatization, uncovering how the coercive dominant discourse which pushes many youths towards attraction to violence is operating within diverse contexts, types of relationships, and gender identities.

\section{Discussion}

In this study, we have investigated the preferences of young female adolescents towards either violent or non-violent profiles of boys, and specifically, for which type of relationship (hooking up or having a stable relationship) they choose one profile or the other to more frequently. The general aim of the research was to explore for which type of relationship the violent profiles are mostly preferred. Related to previous qualitative research about dating violence and the existence of a coercive dominant discourse that pushes many youths to be socialized into linking attraction to violence, this could occur in cases of hooking up and could be linked with cases of gender violence victimization. In a first approach, the results predictably show that non-violent profiles are much preferred to violent profiles. This is a positive observation. However, data from this quasi-experiment needs to 


\section{Table 5 Cross tables hooking up/stable relationship, Boy 2 [non-violent]}

\section{Crosstab 5.1: yourself}

\begin{tabular}{|c|c|c|c|}
\hline \multirow[t]{4}{*}{ Would you like to hook up with him at a party? } & \multicolumn{3}{|c|}{ Would you like to have a relationship with him? } \\
\hline & No & Yes & Total \\
\hline & 4 & 45 & 49 \\
\hline & $8.2 \%$ & $91.8 \%$ & $100 \%$ \\
\hline \multicolumn{4}{|l|}{ Pearsons chi-square analyses of cross tab 5.1} \\
\hline & Value & $\mathrm{df}$ & Asymp. Sig. (2-sided) \\
\hline Pearsons chi-square & $17,296^{a}$ & 1 & 0.000 \\
\hline Continuity correction ${ }^{b}$ & 15,473 & 1 & 0.000 \\
\hline \multicolumn{4}{|l|}{ Crosstab 5.2: your friends } \\
\hline \multirow[t]{4}{*}{ Would your friends like to hook up with him at a party? } & \multicolumn{3}{|c|}{ Would your friends like to have a relationship with him? } \\
\hline & No & Yes & Total \\
\hline & 4 & 56 & 59 \\
\hline & $6.8 \%$ & $93.2 \%$ & $100 \%$ \\
\hline \multicolumn{4}{|l|}{ Pearsons chi-square analyses of cross tab 5.2} \\
\hline & Value & $\mathrm{df}$ & Asymp. Sig. (2-sided) \\
\hline Pearsons chi-square & $10,653^{c}$ & 1 & 0.001 \\
\hline Continuity correctiond & 8960 & 1 & 0.003 \\
\hline \multicolumn{4}{|l|}{ Crosstab 5.3: other girls you know } \\
\hline \multirow[t]{4}{*}{ Would other girls you like to know hook up with him at a party? } & \multicolumn{3}{|c|}{ Would other girls you know like to have a relationship with him? } \\
\hline & No & Yes & Total \\
\hline & 6 & 58 & 64 \\
\hline & $9.4 \%$ & $90.6 \%$ & $100 \%$ \\
\hline \multicolumn{4}{|l|}{ Pearsons chi-square analyses of cross tab 5.3} \\
\hline & Value & $\mathrm{df}$ & Asymp. Sig. (2-sided) \\
\hline Pearsons chi-square & $20,847^{e}$ & 1 & 0.000 \\
\hline Continuity correction ${ }^{f}$ & 18,679 & 1 & 0.000 \\
\hline $\begin{array}{l}\text { ao cells }(0.0 \%) \text { have expected count less than } 5 \text {. The minimum expected count is } 1323 \\
\text { bComputed only for a } 2 \times 2 \text { table } \\
\text { c } 0 \text { cells }(0.0 \%) \text { have expected count less than } 5 \text {. The minimum expected count is } 6.97 \\
{ }^{d} \text { Computed only for a } 2 \times 2 \text { table } \\
\text { eo cells }(0.0 \%) \text { have expected count less than } 5 \text {. The minimum expected count is } 8,64 \\
{ }^{f} \text { Computed only for a } 2 \times 2 \text { table }\end{array}$ & & & \\
\hline
\end{tabular}

be analysed in detail and in a disaggregated manner per type of men (violent vs non-violent) and type of sexual affective relationship (hook-ups vs stable), as other patterns emerged related to preferences for boys with violent attitudes and behaviours specifically in hook-ups reveal which are the sites in which more awareness should be raised and taken into account when designing gender violence prevention campaigns. In this regard, three trends have been observed, which, when discussed in relation to previous scientific literature, can serve us to better understand risk factors underlying gender violence victimization. In turn, they can shed light on recommendations to better orient preventive interventions and more gender-responsive penal sanctions (Burman and Gelsthorpe, 2017).

The first trend observed in the study is that boys with violent behaviours and attitudes, because of the dominant discourse that fosters attraction towards violence, are more coercively preferred for hook-ups than for stable relationships. Frequency analyses and cross-tabulation analyses show that, while many female adolescent participants in the study would reject this type of boy for a stable relationship, they would still choose him for hooking up. A similar trend has also been suggested by research literature in the field of psychology. Authors observed that boys who look more masculine and who have higher 'appetite aggression' (associating masculinity with violent traits) are preferred to a higher extent by some women in the case of short-term relationships but not for long-term relationships (Giebel et al. 2013). Looking at our case studies according to this psychological perspective, some would argue that those girls who choose boys who show violent behaviours and attitudes are characterized by being sensation-seeking individuals who want to escape boredom, even though they are risking falling victim of violence. Following this type of interpretation would yield an explanation as to why some girls still choose boys with aggressive traits. However, this type of interpretation leaves scarce room to deeply understand and question those coercive elements behind girls' preferences and choices, which are shaped by the aforementioned dominant model of socialization.

Prior evidence obtained in the light of the preventive socialization approach provides us with a broader understanding of how a coercive dominant discourse (the one present and spread by mainstream media and main agents of socialization) that, based on unequal gender power-relations, influences a socialization that pushes some adolescents to link attractiveness to persons who have violent attitudes and behaviours (such as the ones described in the vignettes), while violence-free relationships are perceived as 'convenient' but not exciting. Thus, according to the strand of research in which this investigation is framed, one core underlying element shaping many girls' likes and coerced choices towards boys with violent attitudes and behaviours is this dominant discourse (Racionero-Plaza et al., 2018). Further research needs to be carried out in order to better understand through which mechanisms this discourse operates as a risk factor for gender violence victimization, shedding light on how to challenge it.

The explicit description of violent traits such as 'He (...) can't even remember their names after hooking up with them...' (boy 1 ), and 'You will probably be just another girl he's been with but most are not ashamed to admit they dream to be the one to save 


\section{Table 6 Cross tables hooking up/Stable relationship, Boy 4 [non-violent]}

\section{Crosstab 6.1: yourself}

\begin{tabular}{|c|c|c|c|}
\hline \multirow[t]{4}{*}{ Would you like to hook up with him at a party? } & \multicolumn{3}{|c|}{ Would you like to have a relationship with him? } \\
\hline & No & Yes & Total \\
\hline & 6 & 43 & 49 \\
\hline & $12.2 \%$ & $87.8 \%$ & $100 \%$ \\
\hline \multicolumn{4}{|l|}{ Pearsons chi-square analyses of cross tab 6.1} \\
\hline & Value & $\mathrm{df}$ & Asymp. Sig. (2-sided) \\
\hline Pearsons Chi-Square & $28,028^{a}$ & 1 & 0.003 \\
\hline Continuity correction ${ }^{b}$ & 25,883 & 1 & 0.006 \\
\hline \multicolumn{4}{|l|}{ Crosstab 6.2: your friends } \\
\hline \multirow[t]{4}{*}{ Would your friends like to hook up with him at a party? } & \multicolumn{3}{|c|}{ Would your friends like to have a relationship with him? } \\
\hline & No & Yes & Total \\
\hline & 7 & 44 & 51 \\
\hline & $13.7 \%$ & $86.3 \%$ & $100 \%$ \\
\hline \multicolumn{4}{|l|}{ Pearsons chi-square analyses of cross tab 6.2} \\
\hline & Value & $\mathrm{df}$ & Asymp. Sig. (2-sided) \\
\hline Pearsons Chi-Square & $24,188^{a}$ & 1 & 0.000 \\
\hline Continuity correctiond & 22,193 & 1 & 0.000 \\
\hline \multicolumn{4}{|l|}{ Crosstab 6.3: other girls you know } \\
\hline \multirow[t]{4}{*}{ Would other girls you like to know hook up with him at a party? } & \multicolumn{3}{|c|}{ Would other girls you know like to have a relationship with him? } \\
\hline & No & Yes & Total \\
\hline & 4 & 50 & 54 \\
\hline & $7.4 \%$ & $92.6 \%$ & $100 \%$ \\
\hline \multicolumn{4}{|l|}{ Pearsons chi-square analyses of cross tab 6.3} \\
\hline & Value & $\mathrm{df}$ & Asymp. Sig. (2-sided) \\
\hline Pearsons chi-square & $39,286^{e}$ & 1 & 0.000 \\
\hline Continuity correction ${ }^{f}$ & 36,694 & 1 & 0.000 \\
\hline 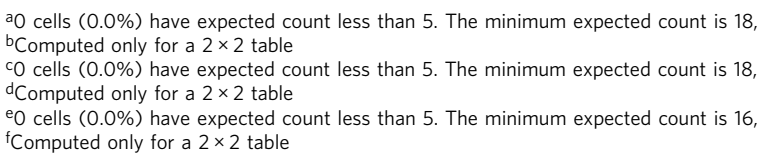 & & & \\
\hline
\end{tabular}

him' (boy 3), shows how these types of boys with violent profiles perceive girls with whom they stay. What Wollstonecraft (1972) named as the brutish nature of men is unveiled in these two vignettes, describing a type of boy and man who is the one looking to dominate 'docile' women, looking to keep them in the dark, in the author's words. Thus, the two boys described as having violent traits, boy 1 and boy 3 , clearly respond to the dominant traditional masculinity model: they have a dominant personality, they despise girls with whom they have sexualaffective relationships, and they match the profile of potential offenders (Banyard et al., 2005). However, even though they are being described with these characteristics, evidence obtained in this investigation reveals that some female study participants, regardless of their different geographic and cultural context, still do not reject them as potential boys with whom they would establish some type of relationship, either stable or hook-up. Nonetheless, the glamour and desire with which these boys are perceived by some girls when considered for hooking up is less apparent when they think about the potential for a stable relationship. In line with previous research, this suggests that many female participants see the potential threat when considering establishing a stable relationship with boys with violent attitudes and behaviour, but they seem not to process hook-ups with violent males as threatening situations.

As mentioned above, a different trend occurs with boys described as non-violent: when compared with what occurs with the violent profiles, the same boy is preferred to a higher extent for stable relationships rather than for hooking up. However, as revealed by the crosstab analysis, among those girls who would choose a non-violent boy for a hook-up, most of them would also choose him for a stable relationship. This is in line with our argumentation, as those girls who have not fallen victims to the coercive dominant discourse which socializes many youths to perceive what is violent as attractive still choose a non-violent boy and do so for different types of relationships. This is consistent with the idea that what gender violence prevention campaigns need to emphasize is not the type of relationship that adolescents establish-either sporadic or stable-but the chosen person.

Solely looking at the scenarios of the boys with violent traits, which are the ones of interest when analysing the patterns underlying potential situations of gender violence victimization, the second trend observed was that female participants revealed higher preferences for the violent profiles when they were answering thinking about the preferences of 'other girls' they know, or 'their friends', rather than when thinking about their own preferences. This is both shown in frequency analysis and confirmed by crosstabulation analyses. Regarding the answers for hooking up with boys with violent attitudes and behaviours for 'other girls they know', percentages are considerably higher, in most of the cases being as high as $50 \%$. More research in the framework of the Free_Teen_Desire project is being done in order to better explicate why this trend occurs. The most reliable hypothesis is the one associated with what occurs when some girls fall victims of the 'mirage of upward mobility' (Tellado et al., 2014).

In these cases, girls are more capable of identifying when their friends are undergoing through this distorted reality than when it is happening to themselves. This does not mean that they do not fall for a mirage but that they may have an impaired ability to recognize these potentially threatening situations (Bramsen et al., 2011; Messman-Moore and Brown, 2006). Taking this into 
account, and taking into account that peers tend to have similar preferences (Braun and Davidson, 2017) while exerting a high influence in dating violence perpetration (Leen et al., 2013; Theobald et al., 2016; Tapp and Moore, 2016), it could be expected that actual preferences of female participants in this type of survey are better reflected when they do not answer for themselves. This suggests that their preferences might be higher than what they have reported about themselves. In any case, what lies behind this second trend should be explored in much detail, analysing to what extent girls are open to recognizing potential risk situations in their own dating relationships.

Finally, the quantitative data collected for this study sheds light on how a similar pattern of attraction can be identified among the different secondary schools in which the study has been conducted. This trend overcomes the fake assumptions that sometimes correlate higher rates of gender violence with certain countries' cultural aspects. This is another aspect that deserves exploration in more detail, deepening our understanding of why the coercive and dominant socialization model is unevenly present among different geographical and cultural contexts and socioeconomic conditions.

Taking into account that the study has been carried out with girls aged 13-16 years old, what can be considered early-teenage and teenage years, this study reveals that for many of them there is a dominant socialization of a model of male attractiveness that imposes on them the association between attractiveness and violence. In this sense, maintaining that both young girls and boys are able of challenging this dominant socialization while questioning the coercive discourse described in the vignettes is a necessary step in order to prevent and tackle gender violence. For this to occur, an alternative discourse needs to be raised within the different spaces of dialogue and interaction in which youths participate, incorporating the 'language of desire' and bringing the focus back to the realm of alternative models of attraction, that is, showing that everyone can have passionate and violencefree relationships (Flecha et al., 2013).

Violence prevention campaigns need to take the insights observed about hooking up and potential situations of dating violence into account in order to better challenge the imposed dominant socialization, meanwhile ensuring that girls and young women who are already victims of gender violence are not revictimized. Moreover, the incorporation of this type of analysis about types of boys and types of relationships into existing criminological research on gender violence provides a new perspective which, which sheds light on the association between violence, attraction and desire, and unveils a clue of utmost importance for advancing towards a more gender-sensitive penal system.

\section{Data availability}

The datasets generated during and/or analysed during the current study are not publicly available due to the involvement of minors in the research. However, they are available from the corresponding author on reasonable request.

Received: 19 June 2018 Accepted: 24 April 2019

Published online: 28 May 2019

\section{References}

Aguinis H, Bradley KJ (2014) Best practice recommendations for designing and implementing experimental vignette methodology studies. Organ Res Methods 17(4):351-371

Banyard VL, Plante EG, Cohn ES, Moorhead C, Ward S, Walsh W (2005) Revisiting unwanted sexual experiences on campus: a 12-year follow-up. Violence Women 11(4):426-446
Barter C, Renold E (1999) The use of vignettes in qualitative research. Soc Res update 25(9):1

Bramsen RH, Lasgaaard M, Elklit A, Koss MP (2011) The development and psychometric assessment of the adolescent sexual coercion risk scale. J Interpers Violence 26(8):1524-1540

Bramsen RH, Lasgaard M, Koss MP, Elklit A, Banner J (2012) Adolescent sexual victimization: A prospective study on risk factors for first time sexual assault. Eur Child Adolesc Psychiatry 21(9):521-526

Braun S, Davidson A (2017) Gender (non)conformity in middle childhood: a mixed methods approach to understanding gender-typed behavior, friendship, and peer preference. Sex Roles 77(1-2):16-29

Burke Draucker C, Martsolf DS, Stephenson P, Heckman T, Ferguson CP, Perkins J, Benson Cook C (2012) Types of aggressive relationships in adolescent dating violence. J Aggress, Maltreatment Trauma 21(5):516-539

Burman M, Gelsthorpe L (2017) Feminist criminology: inequalities, powerlessness, and justice. In: Liebling A, Maruna S, McAra L (eds) The oxford handbook of criminology. Oxford University Press, Oxford, p 213-238

Connell R (2012) Masculinity research and global change. Masc Soc Change 1 (1):4-18

Crawford M, Popp D (2003) Sexual double standards: a review and methodological critique of two decades of research. J Sex Res 40(1):13-26

Erickson MJE, Gittelman MA, Dowd D (2010) Risk factors for dating violence among adolescent females presenting to the pediatric emergency department. J Trauma Acute Care Surg 69(4):S227-S232

European Agency for Fundamental Rights [FRA] (2014) Violence against women an EU-wide survey. http://fra.europa.eu/en/publication/2014/violenceagainst-women-eu-wide-survey-main-results-report. Accessed 12 May 2018

Exner-Cortens D, Eckenrode J, Rothman E (2013) Longitudinal associations between teen dating violence victimization and adverse health outcomes. Pediatrics 131(1):71-8

Fisher BS, Cullen FT, Turner MG (1999) Extent and nature of the sexual victimization of college women: a national-level analysis (final report). U.S Department of Justice, Bureau of Justice Statistics, Washington, DC

Flecha A, Puigvert L (2010) Contributions to social theory from dialogic feminism. In: Chapman P (ed.) Teaching social theory. Peter Lang, New York, NY

Flecha R, Puigvert L, Rios O (2013) The new alternative masculinities and the overcoming of gender violence. Int Multidiscip J Soc Sci 2(1):88-113

Gelsthorpe L (2017) Equal and Different. Scottish Justice Matter 5(2):8-9

Giebel G, Weierstall R, Schauer M, Elbert T (2013) Female attraction to appetitiveaggressive men is modulated by women's menstrual cycle and men's vulnerability to traumatic stress. Evolut Psychol 11(1):248-262

Giebel G, Moran J, Schawohl A, Weierstall R (2015) The thrill of loving a dominant partner: Relationships between preference for a dominant mate, sensation seeking, and trait anxiety. Pers Relatsh 22(2):275-284

Gómez J (2015) Radical love. A revolution for the 21st century, 1st ed. Peter Lang, New York, NY

Gross AM, Winslett A, Roberts M, Gohm CL (2006) An examination of sexual violence against college women. Violence Women 12(3):288-300

Helm S, Baker CK, Berlin J, Kimura S (2015) Getting in, being in, staying in, getting out. Adolescents' perceptions of dating and dating violence. Youth Soc 49 (3):1-23

Houser JJ, Mayeux L, Cross C (2015) Peer status and aggression as predictors of dating popularity. J Youth Adolesc 44(3):683-695

Kalof L, Eby KK, Matheson JL, Kroska RJ (2001) The influence of race and gender on student self-reports of sexual harassment by college professors. Gend Soc 15(2):282-302

Leen E, Sorbring E, Mawer M, Holdsworth E, Helsing B, Bowen E (2013) Prevalence, dynamic risk factors and the efficacy of primary interventions for adolescent dating violence: an international review. Aggress Violent Behav 18 (1):159-174

Limoncelli S (2017) The global development of contemporary anti-human trafficking advocacy. Int Sociol 32(6):814-834

Lundgren R, Amin A (2015) Addressing intimate partner violence and sexual violence among adolescents: emerging evidence of effectiveness. J Adolesc Health 56(1):S42-50

Messman-Moore T, Brown A (2006) Risk perception, rape and sexual revictimization: a prospective study of college women. Psychol Women Q 30 (2):159-172

Oliver E (2010-2012) El espejismo del ascenso social y socialización de la violencia de género. [The mirage of upward mobility and socialisation of gender violence]. Plan Nacional I $+\mathrm{D}+\mathrm{i}$. Ministerio de Ciencia e Innovación

Puigvert L (2014) Preventive socialization of gender violence moving forward using the communicative methodology of research. Qual Inq 2(7):839-843

Puigvert L (2015-2016) Free_Teens_Desire Project. Marie Sklodowska-Curie, EU Horizon 2020 Research and Innovation Programme. Grant agreement No. 659299

Racionero-Plaza S, Ugalde-Lujambio L, Puigvert L, Aiello E (2018) Reconstruction of autobiographical memories of violent sexual-affective relationships through 
scientific reading on love: a psycho-educational intervention to prevent gender violence. Front Psychol. https://doi.org/10.3389/fpsyg.2018.01996

Rios-González O, Peña Axt JC, Duque Sánchez E, De Botton L (2018) The language of ethics and double standards in the affective and sexual socialization of youth. Communicative acts in the family environment as protective or risk factors of intimate partner violence. Front Sociol. https://doi.org/10.3389/ fsoc. 2018.00019

Rebellon CJ, Manasse M (2004) Do 'bad boys' really get the girls? Delinquency as a cause and consequence of dating behavior among adolescents. Justice Q 21 (4):355-389

Sleed M, Durrheim K, Kriel A, Solomon V, Baxter V (2002) The effectiveness of the vignette methodology: a comparison of written and video vignettes in eliciting responses about date rape. South Afr J Psychol 32(3):21-28

Soler-Gallart M (2008-2011) Impacto de los actos comunicativos y nuevas masculinidades [Impact of communicative acts and new masculinities] Ministerio de Ciencia e Innovación. Dirección General de Programas y Transferencia de Conocimiento. Plan Nacional I+D+I

Soler-Gallart M (2017) Achieving social impact. Sociology in the public sphere. Springer, Switzerland. https://doi.org/10.1007/978-3-319-60270-7

Tapp J, Moore E (2016) Risk assessments for dating violence in mid to late adolescence and early adulthood. Crim Behav Ment Health 26(4):278-292

Tellado I, López-Calvo L, Alonso-Olea MJM (2014) Dialogic design of qualitative data collection for researching the mirage of upward mobility. Qual Inq 20 (7):856-862

Theobald D, Farrington D, Ttofi M, Crago R (2016) Risk factors for dating violence versus cohabiting violence: results from the third generation of the Cambridge study in delinquent development. Crim Behav Ment Health 26 (4):229-239

Vidu A, Tomás-Martínez G (2019) The affirmative 'Yes'. Sexual offense based on consent. Masc Soc Change 8(1):91-112

Williams TS, Connolly J, Pepler D, Craig W, Laporte L (2008) Risk models of dating aggression across different adolescent relationships: a developmental psychopathology approach. J Consult Clin Psychol 76(4):622-632

Wollstonecraft M (1972). A vindication of the rights of woman: with strictures on political and moral subjects. J. Johnson, London

World Health Organization (2014) Global and regional estimates of violence against women: prevalence and health effects of intimate partner violence and non-partner sexual violence. http://www.who.int/reproductivehealth/ publications/violence/9789241564625/en/. Accessed 12 May 2018

\section{Funding}

This work received funding from the European Union's Horizon 2020 research and innovation programme under the Marie Sklodowska-Curie grant agreement No 659299 The funders had no role in study design, data collection and analysis, decision to publish, or preparation of the manuscript.

\section{Additional information}

Competing interests: The authors declare that the research was conducted in the absence of any commercial or financial relationships that could be construed as competing interests.

Ethics approval: As explained in the Methods section, dataset used in the current study was approved by the Ethics Committee involved in the evaluation of Marie SklodowskaCurie Actions (H2020 Rules for Participation, Art. 14. Official Journal of the EU 2013). All subjects were informed about the research and gave voluntary written informed consent in accordance with the Declaration of Helsinki (World Medical Association 2013).

Reprints and permission information is available online at http://www.nature.com/ reprints

Publisher's note: Springer Nature remains neutral with regard to jurisdictional claims in published maps and institutional affiliations.

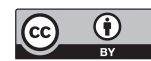

Open Access This article is licensed under a Creative Commons Attribution 4.0 International License, which permits use, sharing, adaptation, distribution and reproduction in any medium or format, as long as you give appropriate credit to the original author(s) and the source, provide a link to the Creative Commons license, and indicate if changes were made. The images or other third party material in this article are included in the article's Creative Commons license, unless indicated otherwise in a credit line to the material. If material is not included in the article's Creative Commons license and your intended use is not permitted by statutory regulation or exceeds the permitted use, you will need to obtain permission directly from the copyright holder. To view a copy of this license, visit http://creativecommons.org/ licenses/by/4.0/.

(C) The Author(s) 2019 